Check for updates

Cite this: RSC Adv., 2019, 9, 27347

Received 27th June 2019

Accepted 20th August 2019

DOI: $10.1039 / c 9 r a 04848 k$

rsc.li/rsc-advances

\section{Investigation on the quality diversity and quality- FTIR characteristic relationship of sunflower seed oils}

\author{
Yang Yi, (D) ${ }^{a}$ Juan Yao, ${ }^{a}$ Wei Xu, ${ }^{a}$ Li-Mei Wang ${ }^{b}$ and Hong-Xun Wang (D)*b
}

Forty-one sunflower seed oil (SSO) products were collected to investigate their quality parameters before and after high-temperature and short-time (HTST) cooking, including peroxide value (PV), acid value (AV) and fatty acid (FA) composition. Their Fourier-transform infrared (FTIR) spectra were then scanned to explore the parameter-FTIR characteristic relationship using chemometrics with multiple linear regression (MLR) analysis. The PV and AV of uncooked products were in the range of $1.49-6.29 \mathrm{mmol}$ $\mathrm{kg}^{-1}$ and $0.04-0.31 \mathrm{mg} \mathrm{g}^{-1}$, with the variation coefficient of $36.47 \%$ and $146.82 \%$, respectively. They were mainly composed of palmitic acid (2.39-3.33\%), stearic acid (1.76-2.54\%), oleic acid (10.02$24.77 \%)$ and linoleic acid (66.42-83.62\%). The parameter changes caused by HTST cooking were slight. SSO products from different countries might have significantly different FA composition, especially linoleic acid content $(P<0.05)$, and those with different shelf times might differ in $\mathrm{PV}(P<0.05)$. In addition, the FTIR spectra of cooked and uncooked SSO showed the similarity degree values ranging from 0.67 to 0.97 and 0.72 to 0.97 , respectively. All the spectra exhibited the characteristic bands of $-\mathrm{C}-\mathrm{H},-\mathrm{C}=\mathrm{O},-\mathrm{C}-\mathrm{O}-$ and $=\mathrm{CH}_{2}$, in which 11 common bands as independent variables were selected to establish various FTIR characteristic-quality relationship models. The models of palmitic acid, oleic acid and linoleic acid were acceptable for their content predictions. Moreover, the cooked oils and uncooked oils could be completely distinguished by orthogonal partial least squares discriminant analysis due to the cooking-caused changes in FTIR spectrum. Production place and shelf time were the important factors related to the quality diversity of SSO, and FTIR spectroscopy combined with chemometrics was feasible for the simultaneous determination of various quality parameters.

\section{Introduction}

Sunflower seed oil (SSO), mostly produced in the Russian Federation, Ukraine, Argentina and Turkey, is one of the most consumed edible oils (about 8.6 million tons per year). ${ }^{1}$ It is recognized as a healthy choice due to balanced amounts of fatty acids (FA) and high contents in polyunsaturated fatty acids (PUFA, account for $68-72 \%$ of total FA), $\alpha$-tocopherol and vitamin E. ${ }^{2,3}$ There is a huge market demand for imported SSO in China. In the last decade, the total imported amount of edible oils ranged from 7.4 to 9.6 million tons per year, in which SSO ranked the third (more than 0.43 million tons per year since 2013), after palm oil and rapeseed oil., ${ }^{4,5}$ The quality of imported SSO products, which have a larger amount compared to the homemade products, ${ }^{5}$ is of wide concern to Chinese consumers.

${ }^{a}$ College of Food Science \& Engineering, Wuhan Polytechnic University, Wuhan 430023, PR China.E-mail: yiy86@whpu.edu.cn; Yaoj1995@163.com; xuwei1216@ $163 . \mathrm{com}$

${ }^{b}$ College of Biology and Pharmaceutical Engineering, Wuhan Polytechnic University, Wuhan 430023, PR China. E-mail: wanghongxun7736@163.com; wanglimeiyx@ 163.com; Tel: +862783955611
The quality of edible oils has been reported to be associated with various factors, such as raw material, technology, additive, storage time and conditions., ${ }^{\mathbf{1 , 2}, \mathbf{6}}$ The oils of wild sunflower seeds harvested from several regions of Argentina showed significant differences in fatty acid (FA) profile, peroxide value (PV) and oxidative stability, as well as those of cultivated sunflower seeds. ${ }^{6}$ In addition, SSO products from the Italian market obviously differed in free acidity, PV, oleic acid content and linoleic acid content, due to the different farming systems of raw material and the different technologies of production. ${ }^{2}$ However, we know limitedly about the quality characteristics of SSO products in the Chinese market, especially the difference between homemade and imported products in consideration of the variations in raw material and technology and the potential effect of cross-border transportation on quality.

In the traditional Chinese cuisine, vegetable oils are used mostly for making vegetable salads, stir-frying, pan-frying and deep-frying. ${ }^{9}$ Stir-frying and pan-frying, which are both characterized with high-temperature and short-time (HTST), are most popular and frequent in the daily Chinese cooking. ${ }^{10}$ Because of relatively high PUFA content, SSO is vulnerable to thermooxidative degradation, which is directly related to the 
deterioration of quality. The quality changes of vegetable oils after cooking have attracted great attentions, particularly many efforts have been paid to investigate the influence of deep-frying (150-200 ${ }^{\circ} \mathrm{C}, \geq 0.5 \mathrm{~h}$ ) on the characteristics of SSO. ${ }^{7,11-13}$ However, the effect of HTST cooking is still unavailable.

Many analytical methods have been proposed for the quality control of edible oils, in which Fourier-transform infrared (FTIR) spectroscopy is a rapid, nondestructive and environmental-friendly technique widely used in research laboratories and food industry to characterize oils with specific bands or regions in spectrum. ${ }^{\mathbf{1 4 , 1 5}}$ Certain FTIR bands have been applied for the qualitative determination of some parameters such as free FA, PV, saturated and monounsaturated acyl groups. ${ }^{16-19}$ In comparison, certain FTIR regions have been reported with more applications in the quality control using chemometrics methods, involving in adulteration, deterioration, authentication and quality prediction..$^{20-23}$ The deep-fryingcaused deterioration of SSO and its adulteration with deteriorated oils have been clearly defined by FTIR spectroscopy combined with chemometrics. ${ }^{15}$ To the best of our knowledge, there is no systematic investigation on the FTIR profile difference between SSO products and the relationship between FTIR characteristic and quality.

The present work aimed to preliminarily investigate the quality diversity of SSO products consumed in China, evaluate the effect of HTST cooking on their qualities, and explore the FTIR characteristic-quality relationship of SSO. Therefore, available SSO products in the Chinese market were collected. Their quality parameters, including PV, AV and FA, were analyzed before and after HTST cooking. Moreover, their common bands of FTIR spectrum confirmed by chemometrics analysis were used as independent variables to establish the multiple linear regression (MLR) models of various parameters. The availability of models used for the quality determination of SSO was further evaluated.

\section{Materials and methods}

\subsection{SSO products}

Forty-one SSO products sold in China were purchased as seen in Table 1. In addition, the products of Aceites Abril (0.5 $\mathrm{L}$ in a PET bottle, Ourense, Spain) were dark-kept at $40{ }^{\circ} \mathrm{C}$ for $0,2,4,6$ and 8 months to obtain the test samples, which were used for verifying the determination method proposed in the present work and were respectively named as S1, S2, S3, S4 and S5. All the tests on SSO products were finished in $12 \mathrm{~h}$ after they were first opened.

\subsection{Cooking treatment}

The HTST cooking of SSO was carried out with three replications for each sample, according to the method reported previously. ${ }^{10} \mathrm{~A}$ cast iron pan was preheated in a $210{ }^{\circ} \mathrm{C}$ oil bath, and SSO $(100 \pm 2 \mathrm{~g})$ was then added in for $5 \mathrm{~min}$ heating. The hot oil was rapidly cooled in an ice-water bath and stored in a well-sealed tube at $4{ }^{\circ} \mathrm{C}$. All the tests on sample were finished in the following $12 \mathrm{~h}$.

\subsection{Quality analyses}

The PV and AV of oil samples were measured by the titration methods described in the national standard GB5009.227 and GB5009.229 of China, respectively. ${ }^{24,25}$ The values of PV were expressed as the molar amount of active oxygen per $1 \mathrm{~kg}$ of sample $\left(\mathrm{mmol} \mathrm{kg}{ }^{-1}\right)$, and those of AV were expressed as the mass of potassium hydroxide used to neutralize $1 \mathrm{~g}$ of sample $\left(\mathrm{mg} \mathrm{KOH} \mathrm{g}^{-1}\right)$. The methyl-esterification of oil samples was implemented according to the national standard GB5009.168 of China using $15 \%$ boron fluoride-methanol solution. ${ }^{26}$ The measurement of FA methyl ester was then performed with an Agilent 7890A gas chromatograph (GC) system (Agilent, Santa Clara, CA, USA). ${ }^{10}$ The chromatographic conditions were as follows: the temperature of Agilent HP-88 capillary column (60 $\mathrm{m}$ length, $0.2 \mathrm{~mm}$ inner diameter and $0.2 \mu \mathrm{m}$ thickness) increased from $100{ }^{\circ} \mathrm{C}$ to $175{ }^{\circ} \mathrm{C}$ at a rate of $15{ }^{\circ} \mathrm{C} \mathrm{min}{ }^{-1}$ (hold for $10 \mathrm{~min}$ ) and then increased to $230^{\circ} \mathrm{C}$ at a rate of $5{ }^{\circ} \mathrm{C} \mathrm{min}{ }^{-1}$ (hold for $20 \mathrm{~min}$ ); $\mathrm{N}_{2}$ was used as carrier gas at a flow rate of 1.0 $\mathrm{mL} \min ^{-1} ; 1 \mu \mathrm{L}$ sample was injected with the splitless mode; the temperature of injection port was $260{ }^{\circ} \mathrm{C}$; the temperature of flame ionization detector (FID) was $280{ }^{\circ} \mathrm{C}$; the flow rates of $\mathrm{H}_{2}$, air and make-up $\mathrm{N}_{2}$ were 30,400 and $30 \mathrm{~mL} \mathrm{~min}^{-1}$, respectively. The standard mixture of FA methyl esters (Sigma Aldrich Co Ltd, Bellefonte, PA, USA) was gradient-diluted to establish the standard curve (concentration $v s$. peak area). For each sample, all the measurements were performed in triplicate.

\subsection{FTIR measurement}

Attenuated total reflectance-Fourier transform infrared spectroscopy (ATR-FTIR) was used to characterize oil samples on a Thermo Nicolet Nexus 670 FTIR spectrometer (Nicolet Instrument Corporation, Madison, USA) in the range of 4000$600 \mathrm{~cm}^{-1}$ with a resolution of $4 \mathrm{~cm}^{-1}$. The sample $(50 \mu \mathrm{L})$ was scanned by a deuterated triglycine sulfate detector with the signal cumulative frequency of 16 .

\subsection{Statistical analysis}

Data were presented as means \pm standard deviations. The significant difference $(P<0.05)$ between groups was analyzed by one-way analysis of variance (Student-Newman-Keuls test) using the SPSS Statistics 19 software (IBM, Armonk, NY, USA). The between-group correlation was assessed by Pearson's correlation test. The curvilinear integrating, common model fitting, similarity evaluation and multivariate statistical analysis of FTIR spectra were conducted on the ChemPattern software (Advanced Chemometric Solution 2017, Chemmind Technologies (Beijing) CO., LTD., Beijing, China). The relationship between FTIR characteristic and quality parameter was investigated by multiple linear regression (MLR) analysis with the Enter method using the SPSS software.

\section{Results}

\subsection{PV and AV of SSO products}

Both PV and AV are important indices to control the safety and quality of edible vegetable oil. In China, the PV and AV of SSO 
Table 1 The information of sunflower seed oil products

\begin{tabular}{|c|c|c|c|c|c|c|c|c|}
\hline \multirow[b]{2}{*}{$\begin{array}{l}\text { Sample } \\
\text { code }\end{array}$} & \multicolumn{6}{|c|}{ Product information } & \multirow[b]{2}{*}{$\begin{array}{l}\text { Date of test (month/day/ } \\
\text { year) }\end{array}$} & \multirow[b]{2}{*}{$\begin{array}{l}\text { Shelf time }{ }^{c} \\
\text { (month) }\end{array}$} \\
\hline & Country & $\begin{array}{l}\text { Date of } \\
\text { production } \\
\text { (month/day/ } \\
\text { year) }\end{array}$ & $\begin{array}{l}\text { Shelf life } \\
\text { (month) }\end{array}$ & $\begin{array}{l}\text { Packaging } \\
\text { volume (L) }\end{array}$ & Technology $^{a}$ & $\begin{array}{l}\text { Quality } \\
\text { grade }^{b}\end{array}$ & & \\
\hline A1 & Bulgaria & 03/05/2016 & 24 & 5 & $\mathrm{E}$ & - & $12 / 23 / 2017$ & 22 \\
\hline B3 & Turkey & $12 / 03 / 2016$ & 24 & 4 & $\mathrm{P}$ & - & 02/01/2018 & 14 \\
\hline C1 & Spain & $11 / 05 / 2016$ & 24 & 2 & $\mathrm{P}$ & - & 02/01/2018 & 15 \\
\hline $\mathrm{C} 2$ & Spain & 09/28/2016 & 24 & 2 & $\mathrm{E}$ & - & 02/01/2018 & 16 \\
\hline C3 & Spain & 03/29/2016 & 24 & 1 & $\mathrm{P}$ & 1 & 03/27/2018 & 24 \\
\hline $\mathrm{C} 4$ & Spain & 07/11/2016 & 24 & 2 & $\mathrm{P}$ & - & $03 / 27 / 2018$ & 21 \\
\hline C5 & Spain & $01 / 25 / 2016$ & 24 & 1 & $\mathrm{E}$ & - & 03/27/2018 & 26 \\
\hline C10 & Spain & $12 / 10 / 2016$ & 24 & 1 & $\mathrm{E}$ & 1 & 07/03/2018 & 19 \\
\hline C11 & Spain & 09/21/2017 & 24 & 1 & $\mathrm{P}$ & - & 01/03/2019 & 16 \\
\hline D1 & Italy & $10 / 05 / 2016$ & 24 & 0.5 & $\mathrm{P}$ & 1 & $04 / 25 / 2018$ & 19 \\
\hline E1 & Ukraine & 07/15/2016 & 24 & 0.87 & $\mathrm{P}$ & 1 & $04 / 25 / 2018$ & 22 \\
\hline E2 & Ukraine & $11 / 15 / 2016$ & 24 & 5 & $\mathrm{P}$ & - & 05/22/2018 & 18 \\
\hline E3 & Ukraine & $11 / 08 / 2016$ & 24 & 5 & $\mathrm{P}$ & - & $05 / 22 / 2018$ & 19 \\
\hline $\mathrm{E} 4$ & Ukraine & $03 / 20 / 2017$ & 24 & 5 & $\mathrm{P}$ & - & $06 / 25 / 2018$ & 15 \\
\hline E5 & Ukraine & 05/19/2017 & 24 & 5 & $\mathrm{P}$ & - & 07/03/2018 & 14 \\
\hline E6 & Ukraine & $06 / 09 / 2017$ & 24 & 5 & $\mathrm{P}$ & - & $10 / 19 / 2018$ & 17 \\
\hline E7 & Ukraine & 04/11/2017 & 24 & 1 & $\mathrm{P}$ & - & $10 / 19 / 2018$ & 19 \\
\hline E8 & Ukraine & $11 / 23 / 2016$ & 24 & 1 & $\mathrm{E} \& \mathrm{P}$ & - & $12 / 05 / 2018$ & 25 \\
\hline E9 & Ukraine & $01 / 25 / 2017$ & 24 & 1 & $\mathrm{P}$ & - & $12 / 05 / 2018$ & 23 \\
\hline E10 & Ukraine & $05 / 09 / 2016$ & 24 & 5 & $\mathrm{P}$ & 1 & $12 / 05 / 2018$ & 30 \\
\hline I1 & Germany & 07/08/2016 & 18 & 1 & $\mathrm{P}$ & - & $04 / 25 / 2018$ & 22 \\
\hline $\mathrm{I} 2$ & Germany & 07/30/2018 & 24 & 0.75 & $\mathrm{P}$ & - & 01/03/2019 & 5 \\
\hline $\mathrm{J} 1$ & China & $01 / 14 / 2018$ & 18 & 0.9 & $\mathrm{P}$ & 1 & $12 / 13 / 2018$ & 11 \\
\hline $\mathrm{J} 2$ & China & $09 / 30 / 2018$ & 18 & 5 & $\mathrm{P}$ & - & $12 / 19 / 2018$ & 3 \\
\hline $\mathrm{J} 3$ & China & $10 / 31 / 2018$ & 18 & 4 & $\mathrm{P}$ & - & $12 / 19 / 2018$ & 2 \\
\hline $\mathrm{J} 4$ & China & $01 / 20 / 2018$ & 18 & 1.8 & $\mathrm{P}$ & 1 & $12 / 19 / 2018$ & 11 \\
\hline J5 & China & 09/04/2018 & 18 & 0.9 & $\mathrm{P}$ & 1 & $01 / 03 / 2019$ & 4 \\
\hline
\end{tabular}

${ }^{a}$ E, extraction technology; P, pressing technology; sample E8 marked 'E\&P' is a mixed product composed of $75 \%$ pressing oil and $25 \%$ extracting oil. ${ }^{b}$ The labeled grade is in accord with the national standard GB/T 10464-2017 of China, and '-' means that the grade is unavailable. 'Shelf time' means the time span between the dates of production and test of sunflower seed oil product.

are at most $7.5 \mathrm{mmol} \mathrm{kg}^{-1}$ and $1.5 \mathrm{mg} \mathrm{KOH} \mathrm{g}{ }^{-1}$ for first-grade standard, and at most $9.8 \mathrm{mmol} \mathrm{\textrm {kg } ^ { - 1 }}$ and $3.0 \mathrm{mg} \mathrm{g}^{-1}$ for second-grade standard, respectively. ${ }^{27}$ As seen in Table 2, the PV values of uncooked and cooked SSO products were respectively in the ranges of 1.5-6.3 $\mathrm{mmol} \mathrm{kg}^{-1}$ and 1.6-7.1 $\mathrm{mmol} \mathrm{kg}^{-1}$, with the mean values of 3.1 and $3.6 \mathrm{mmol} \mathrm{kg}^{-1}$. Compared with PV values, $\mathrm{AV}$ values showed larger coefficients of variation $(\mathrm{CV}$, $>144 \%$ ). But there were no obvious differences between uncooked and cooked groups in AV range (0.02-1.26 and 0.02$1.28 \mathrm{mg} \mathrm{KOH} \mathrm{g}^{-1}$ ) and mean AV (both $0.18 \mathrm{mg} \mathrm{KOH} \mathrm{g}^{-1}$ ). All the investigated products were in the first-grade standard of PV and AV.

\subsection{FA compositions of SSO products}

As referred to the national standard GB/T 10464 of China, SSO is composed of myristic acid (C14:0, $\leq 0.2 \%)$, palmitic acid (C16:0, 5.0-7.6\%), palmitoleic acid (C16:1, $\leq 0.3 \%)$, heptadecanoic acid (C17:0, $\leq 0.2 \% ; \mathrm{C} 17: 1, \leq 0.1 \%)$, stearic acid (C18:0, 2.7-6.5\%), oleic acid (C18:1, 14.0-39.4\%), linoleic acid (C18:2, 48.3$74.0 \%)$, linolenic acid (C18:3, $\leq 0.3 \%)$, arachidic acid (C20:0, 
Table 2 The peroxide values and acid values of SSO products ${ }^{a}$

\begin{tabular}{|c|c|c|c|c|}
\hline \multirow[b]{2}{*}{ Sample code } & \multicolumn{2}{|c|}{$\begin{array}{l}\text { Peroxide } \\
\text { value }\left(\mathrm{mmol} \mathrm{kg}^{-1}\right)\end{array}$} & \multicolumn{2}{|c|}{ Acid value $\left(\mathrm{mg} \mathrm{KOH} \mathrm{g}{ }^{-1}\right)$} \\
\hline & Uncooked & Cooked & Uncooked & Cooked \\
\hline A1 & $2.2 \pm 0.2$ & $3.7 \pm 0.8$ & $1.18 \pm 0.06$ & $1.14 \pm 0.02$ \\
\hline B1 & $3.2 \pm 0.2$ & $4.1 \pm 0.6$ & $0.15 \pm 0.01$ & $0.16 \pm 0.01$ \\
\hline B2 & $2.4 \pm 0.1$ & $3.7 \pm 0.5$ & $0.05 \pm 0.01$ & $0.05 \pm 0.01$ \\
\hline B3 & $2.5 \pm 0.3$ & $2.8 \pm 0.6$ & $0.06 \pm 0.01$ & $0.06 \pm 0.01$ \\
\hline C1 & $1.9 \pm 0.1$ & $2.5 \pm 0.3$ & $0.21 \pm 0.01$ & $0.20 \pm 0.01$ \\
\hline $\mathrm{C} 2$ & $2.7 \pm 0.2$ & $2.9 \pm 0.3$ & $0.10 \pm 0.01$ & $0.11 \pm 0.01$ \\
\hline C3 & $4.6 \pm 0.4$ & $5.9 \pm 0.3$ & $0.25 \pm 0.01$ & $0.25 \pm 0.01$ \\
\hline $\mathrm{C} 4$ & $3.4 \pm 0.2$ & $4.0 \pm 0.3$ & $0.25 \pm 0.01$ & $0.26 \pm 0.01$ \\
\hline C5 & $2.6 \pm 0.2$ & $3.8 \pm 0.1$ & $0.04 \pm 0.01$ & $0.04 \pm 0.01$ \\
\hline C6 & $2.5 \pm 0.2$ & $3.2 \pm 0.3$ & $0.12 \pm 0.01$ & $0.11 \pm 0.01$ \\
\hline C7 & $3.0 \pm 0.3$ & $3.4 \pm 0.3$ & $0.40 \pm 0.01$ & $0.40 \pm 0.01$ \\
\hline C8 & $2.7 \pm 0.3$ & $3.6 \pm 0.2$ & $0.18 \pm 0.01$ & $0.18 \pm 0.01$ \\
\hline C9 & $3.6 \pm 0.3$ & $4.3 \pm 0.3$ & $0.18 \pm 0.01$ & $0.18 \pm 0.01$ \\
\hline C10 & $4.6 \pm 0.3$ & $3.9 \pm 0.3$ & $0.32 \pm 0.01$ & $0.32 \pm 0.01$ \\
\hline C11 & $2.4 \pm 0.4$ & $2.1 \pm 0.4$ & $0.19 \pm 0.03$ & $0.21 \pm 0.01$ \\
\hline D1 & $2.7 \pm 0.1$ & $3.3 \pm 0.2$ & $0.02 \pm 0.01$ & $0.02 \pm 0.01$ \\
\hline $\mathrm{E} 1$ & $4.9 \pm 0.3$ & $4.9 \pm 0.3$ & $0.06 \pm 0.01$ & $0.06 \pm 0.01$ \\
\hline E2 & $3.2 \pm 0.3$ & $4.2 \pm 0.3$ & $0.05 \pm 0.01$ & $0.05 \pm 0.01$ \\
\hline E3 & $2.8 \pm 0.2$ & $3.9 \pm 0.3$ & $0.09 \pm 0.01$ & $0.10 \pm 0.01$ \\
\hline E4 & $4.3 \pm 0.1$ & $4.5 \pm 0.2$ & $0.07 \pm 0.01$ & $0.08 \pm 0.01$ \\
\hline E5 & $2.1 \pm 0.1$ & $2.6 \pm 0.2$ & $0.09 \pm 0.01$ & $0.10 \pm 0.01$ \\
\hline E6 & $2.2 \pm 0.2$ & $3.2 \pm 0.3$ & $0.06 \pm 0.01$ & $0.06 \pm 0.01$ \\
\hline E7 & $3.7 \pm 0.3$ & $4.1 \pm 0.4$ & $1.26 \pm 0.01$ & $1.28 \pm 0.01$ \\
\hline E8 & $4.1 \pm 0.4$ & $3.1 \pm 0.2$ & $0.04 \pm 0.01$ & $0.05 \pm 0.01$ \\
\hline E9 & $4.2 \pm 0.2$ & $3.8 \pm 0.3$ & $0.17 \pm 0.01$ & $0.17 \pm 0.01$ \\
\hline E10 & $2.0 \pm 0.4$ & $2.2 \pm 0.2$ & $0.07 \pm 0.01$ & $0.07 \pm 0.01$ \\
\hline E11 & $2.1 \pm 0.2$ & $2.9 \pm 0.3$ & $0.16 \pm 0.01$ & $0.16 \pm 0.01$ \\
\hline $\mathrm{F} 1$ & $6.3 \pm 0.6$ & $7.1 \pm 0.5$ & $0.31 \pm 0.01$ & $0.32 \pm 0.01$ \\
\hline F2 & $3.4 \pm 0.2$ & $4.1 \pm 0.8$ & $0.08 \pm 0.01$ & $0.09 \pm 0.01$ \\
\hline G1 & $5.6 \pm 0.3$ & $6.9 \pm 0.4$ & $0.10 \pm 0.01$ & $0.10 \pm 0.01$ \\
\hline $\mathrm{H} 1$ & $3.3 \pm 0.6$ & $4.0 \pm 0.4$ & $0.06 \pm 0.01$ & $0.06 \pm 0.01$ \\
\hline $\mathrm{H} 2$ & $3.8 \pm 0.3$ & $4.0 \pm 0.3$ & $0.44 \pm 0.01$ & $0.44 \pm 0.01$ \\
\hline H3 & $2.4 \pm 0.4$ & $3.1 \pm 0.3$ & $0.09 \pm 0.01$ & $0.10 \pm 0.01$ \\
\hline $\mathrm{H} 4$ & $2.1 \pm 0.4$ & $1.7 \pm 0.5$ & $0.04 \pm 0.01$ & $0.04 \pm 0.01$ \\
\hline I1 & $5.2 \pm 0.5$ & $5.4 \pm 0.6$ & $0.06 \pm 0.01$ & $0.07 \pm 0.01$ \\
\hline I2 & $2.1 \pm 0.3$ & $2.8 \pm 0.6$ & $0.03 \pm 0.01$ & $0.04 \pm 0.01$ \\
\hline $\mathrm{J} 1$ & $2.1 \pm 0.1$ & $2.9 \pm 0.2$ & $0.06 \pm 0.01$ & $0.05 \pm 0.01$ \\
\hline $\mathrm{J} 2$ & $1.9 \pm 0.2$ & $1.8 \pm 0.1$ & $0.03 \pm 0.01$ & $0.03 \pm 0.01$ \\
\hline $\mathrm{J} 3$ & $1.5 \pm 0.1$ & $2.0 \pm 0.1$ & $0.04 \pm 0.01$ & $0.04 \pm 0.01$ \\
\hline $\mathrm{J} 4$ & $2.8 \pm 0.5$ & $2.8 \pm 0.4$ & $0.04 \pm 0.01$ & $0.04 \pm 0.01$ \\
\hline J5 & $2.0 \pm 0.3$ & $1.6 \pm 0.4$ & $0.05 \pm 0.01$ & $0.05 \pm 0.01$ \\
\hline Mean \pm SD & $3.1 \pm 1.2$ & $3.6 \pm 1.3$ & $0.18 \pm 0.27$ & $0.18 \pm 0.26$ \\
\hline
\end{tabular}

${ }^{a}$ Values were expressed as means \pm standard deviation $(n=3)$.

0.1-0.5\%), eicosenoic acid (C20:1, $\leq 0.3 \%)$, behenic acid (C22:0, 0.3-1.5\%), erucic acid (C22:1, $\leq 0.3 \%)$, docosadienoic acid $(\mathrm{C} 22: 2, \leq 0.3 \%)$ and tetracosanoic acid $(\mathrm{C} 24: 0, \leq 0.5 \%) .{ }^{27}$ The 41 SSO products mainly contained palmitic acid (2.39-3.33\%), stearic acid (1.76-2.54\%), oleic acid (10.02-24.77\%) and linoleic acid $(66.42-83.62 \%)$ as seen in Table 3 . In addition, myristic acid $(\leq 0.06 \%)$, palmitoleic acid $(\leq 0.24 \%)$, elaidic acid $(\leq 1.05 \%)$, linolelaidic acid $(\leq 1.16 \%)$, arachidic acid $(\leq 0.35 \%)$, eicosenoic acid $(\leq 0.83 \%$, except sample F2 that had a higher content of $2.71 \%)$, linolenic acid $(\leq 0.23 \%)$, behenic acid $(\leq 0.50 \%)$, docosadienoic acid $(\leq 0.19 \%)$ and eicosapentaenoic acid $(\leq 0.17 \%)$. The HTST cooking did not significantly change the FA composition of SSO.

\subsection{FTIR characteristics of SSO products}

FTIR spectroscopy in combination with chemometrics has been widely applied for the quality control of edible oils. ${ }^{17,23}$ The FTIR spectra of uncooked and cooked SSO products in the wavenumber range of $4000-600 \mathrm{~cm}^{-1}$ were recorded (Fig. 1A and D). The FTIR common models of the two groups, defined as the average vector of spectra, were highly similar (Fig. 1B and E). Their characteristic bands included: the $\mathrm{C}-\mathrm{H}$ stretching vibration (SV) of $=\mathrm{C}-\mathrm{H}($ cis $)$ at $3006.48 \mathrm{~cm}^{-1}$; the symmetric SV of $-\mathrm{C}-\mathrm{H}\left(\mathrm{CH}_{3}\right)$ at $2923.56 \mathrm{~cm}^{-1}$; the asymmetric SV of $-\mathrm{C}-\mathrm{H}\left(\mathrm{CH}_{2}\right)$ at $2854.18 \mathrm{~cm}^{-1}$; the $\mathrm{SV}$ of $-\mathrm{C}=\mathrm{O}$ (ester) at $1745.26 \mathrm{~cm}^{-1}$; the SV of $-\mathrm{C}=\mathrm{O}$ (acid) at $1683.55 \mathrm{~cm}^{-1}$; the bending vibration (BV) of $-\mathrm{C}-\mathrm{H}\left(\mathrm{CH}_{2}\right)$ at $1492.63 \mathrm{~cm}^{-1}$; the scissoring $\mathrm{BV}$ of $-\mathrm{C}-\mathrm{H}\left(\mathrm{CH}_{2}\right)$ at $1463.71 \mathrm{~cm}^{-1}$; the symmetric BV of $-\mathrm{C}-\mathrm{H}\left(\mathrm{CH}_{3}\right)$ at $1378.85 \mathrm{~cm}^{-1}$; the $\mathrm{BV}$ of $\mathrm{CH}_{2}$ group at $1303.64 \mathrm{~cm}^{-1}$; the SV of $-\mathrm{C}-\mathrm{O}-$ at $1241.93 \mathrm{~cm}^{-1}$; the SV of $-\mathrm{C}-\mathrm{O}$ at $1162.87 \mathrm{~cm}^{-1}$; the SV of $-\mathrm{C}-\mathrm{O}$ at $1099.23 \mathrm{~cm}^{-1}$; the BV (C-H out of plane) of $-\mathrm{HC}=\mathrm{CH}-($ trans $)$ at $966.16 \mathrm{~cm}^{-1}$; the wagging vibration of $=\mathrm{CH}_{2}$ at $836.96 \mathrm{~cm}^{-1}$; the rocking vibration of $-\left(\mathrm{CH}_{2}\right)_{n^{-}}$at $721.25 \mathrm{~cm}^{-1}$; and the BV (out of plane) of $\mathrm{O}-\mathrm{H}$ at $636.39 \mathrm{~cm}^{-1} \cdot \cdot^{14,17,23}$ In addition, the $3683.37 \mathrm{~cm}^{-1}$ band might be related to the $-\mathrm{OH} \mathrm{SV}$ of water $(\mathrm{H}-$ $\mathrm{OH})$, hydroperoxides $(\mathrm{ROOH})$ and their breakdown products (namely alcohols ROH). ${ }^{18,19}$

The similarity degree of sample spectrum comparing to common model was calculated by the coefficient of correlation. The values of uncooked oils ranged from 0.67 to 0.97 (Fig. 1C), and those of cooked oils ranged from 0.72 to 0.97 (Fig. 1F). Based on the integrating of spectra performed with the slope value of $0.01,11$ common bands were selected, and their intensities were listed in Table 4 . The spectral differences among the oils mainly appeared at 1464, 1379 and $1240 \mathrm{~cm}^{-1}$. The corresponding bands showed relatively higher coefficients of intensity variation (>18.08\%) compared to others.

To get an insight into the FTIR features responsible for the discrimination between uncooked and cooked oils, a score plot (Fig. 1G) and a loading plot (not shown) were formed by orthogonal partial least squares discriminant analysis (OPLSDA) using the ChemPattern software. The two groups were obviously separated. The FTIR bands mainly contributed to the separation distributed in the fingerprint region $\left(650-630 \mathrm{~cm}^{-1}\right)$, which was associated with the $\mathrm{BV}$ (out of plane) of $\mathrm{O}-\mathrm{H}^{23}$

\subsection{FTIR-based MLR models}

The relationship between the FTIR feature and quality parameter of SSO was analyzed by an MLR method. The FTIR common bands 1-11 were defined to be independent variables $X_{1}-X_{11}$, respectively. The MLR models of $\mathrm{PV}\left(Y_{1}\right), \mathrm{AV}\left(Y_{2}\right)$, palmitic acid content $\left(Y_{3}\right)$, oleic acid content $\left(Y_{5}\right)$ and linoleic acid content $\left(Y_{6}\right)$ were highly significant $(P<0.01)$ and respectively contributed to $63.6 \%, 56.2 \%, 68.7 \%, 78.8 \%$ and $76.3 \%$ of the variations among samples (Table 5). Their standard errors of estimation, which were respectively $1.0 \mathrm{mmol} \mathrm{kg}{ }^{-1}, 0.23 \mathrm{mg} \mathrm{KOH} \mathrm{g}{ }^{-1}, 0.15 \%$, $2.05 \%$ and $2.30 \%$, were acceptable in relative to the actual values. The factors significantly related to the qualities of SSO can be concluded as: $X_{3}$ for $Y_{1} ; X_{1}, X_{2}$ and $X_{8}$ for $Y_{2} ; X_{3}, X_{4}$ and $X_{11}$ for $Y_{3} ; X_{1}, X_{3}, X_{4}, X_{7}, X_{8}$ and $X_{11}$ for both $Y_{5}$ and $Y_{6}$. The mean 


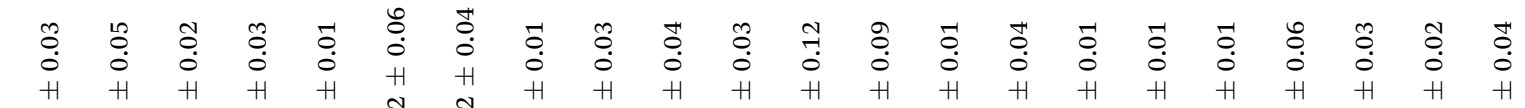

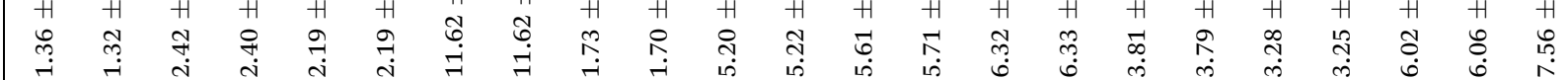




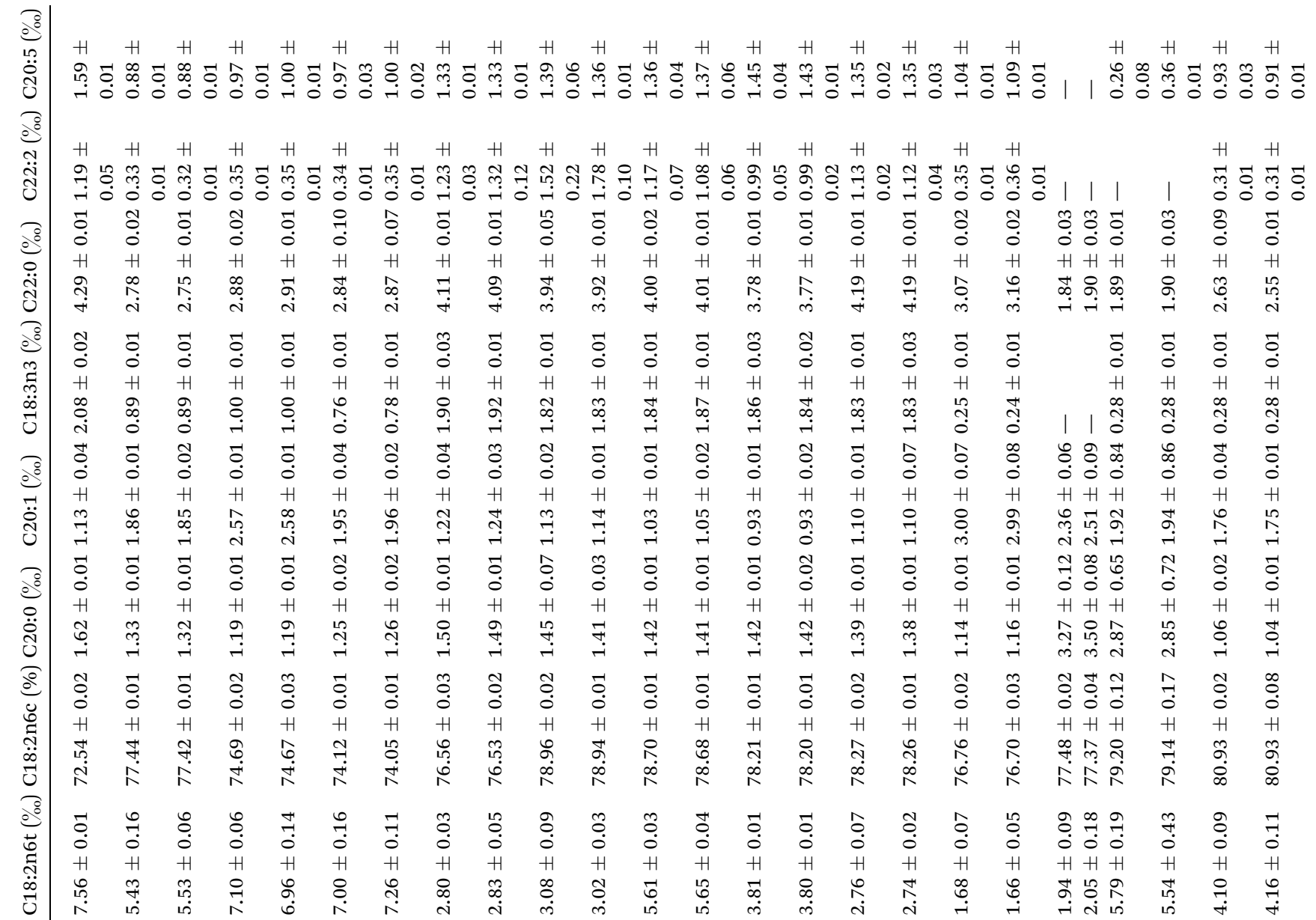




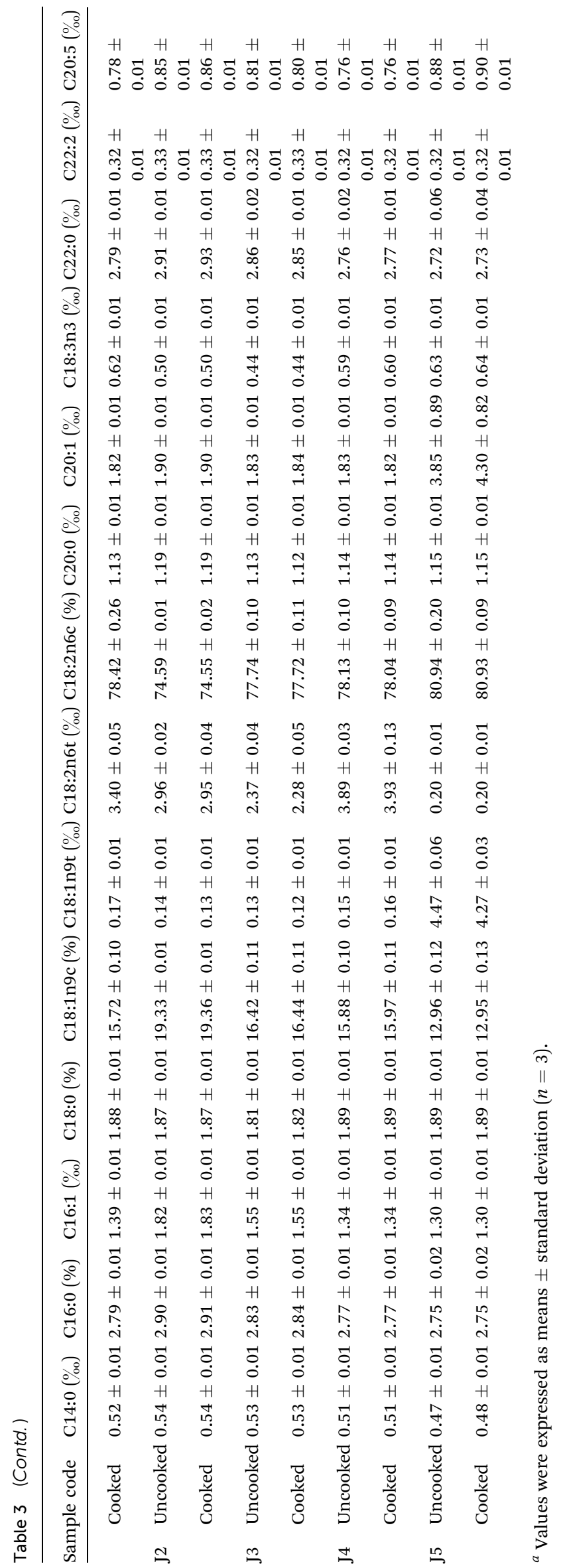



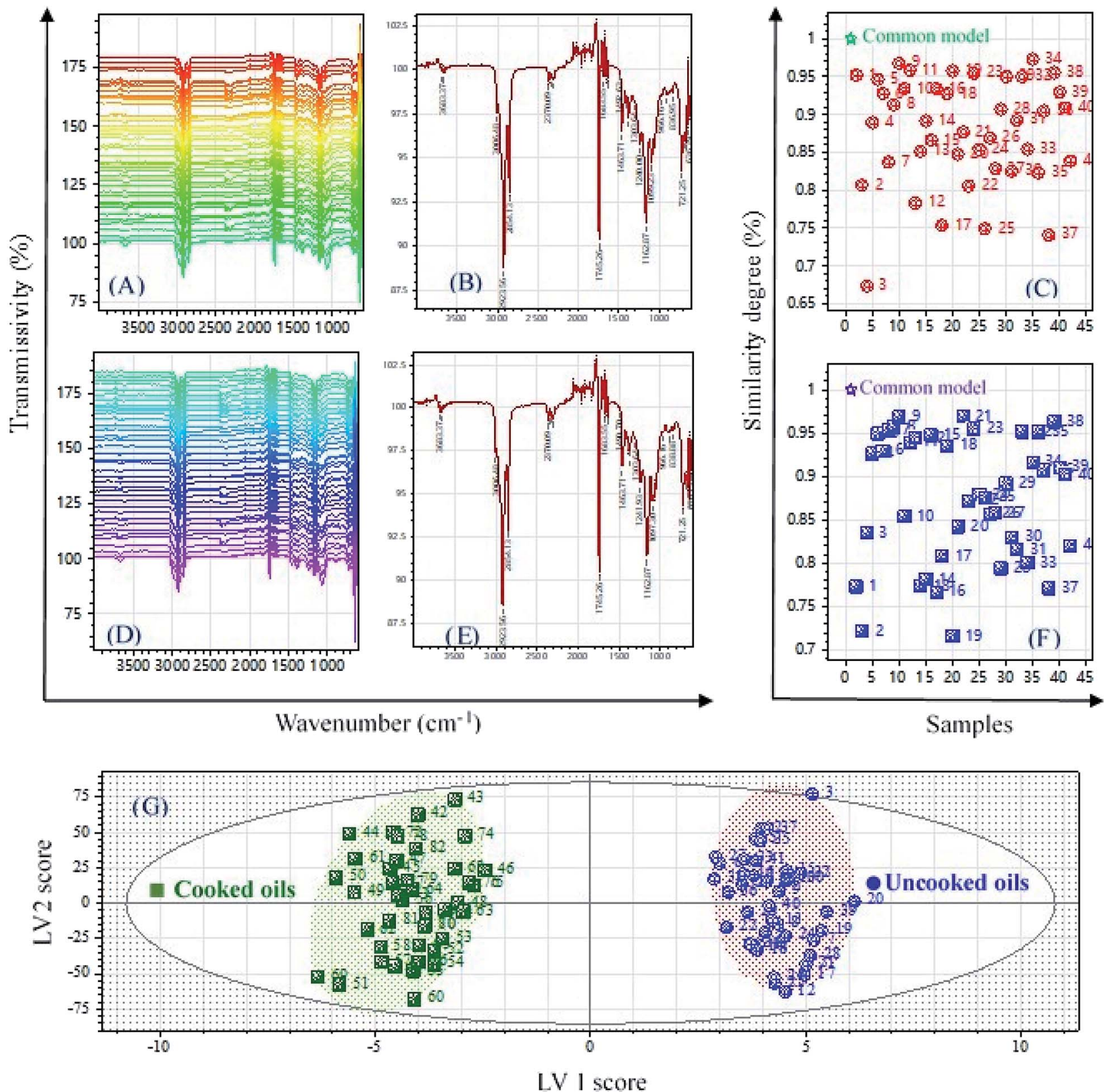

Fig. 1 The FTIR spectra of sunflower seed oil products and their common models, similarity-degree plots and score plot based on orthogonal partial least squares discriminant analysis (OPLS-DA). The overall spectra, common model and similarity-degree plot of uncooked oils are (A), (B) and (C), and those of cooked oil are (D), (E) and (F), respectively. The spectra of samples coded from A1 to J5 are displayed from top down in (A) and $(D)$, and numbered from 1 to 41 in $(C)$ and $(F)$. (G) is the OPLS-DA plot.

values of residuals were nearly zero. As directly observed in the probability plots (not shown), the date $(n=82)$ of PV model were mostly distributed on the diagonal line, and the date of other models were evenly laid close to the diagonal line on the two sides. It was suggested that the residuals of the models basically belonged to normal distribution and the model-based predictions were feasible to some extent.

The model equations were further used for predicting of the quality parameters of SSO samples (S1-5) by calculating with their intensity values of common bands, as seen in Table 6 . Their measured values of PV, AV, palmitic acid content, oleic acid content and linoleic acid content ranged from 1.3 to
$5.2 \mathrm{mmol} \mathrm{kg}^{-1}$, from 0.14 to $0.27 \mathrm{mg} \mathrm{KOH} \mathrm{g}{ }^{-1}$, from $2.52 \%$ to $2.88 \%$, from $16.33 \%$ to $16.77 \%$, and from $76.90 \%$ to $77.45 \%$, respectively. The relative errors of their predicted PV and AV had large ranges of variation $(1.85-57.79 \%$ for $\mathrm{PV}$ and $1.36-288.57 \%$ for AV), by contrast, those of predicted palmitic acid content (3.45-18.03\%), oleic acid content (0.83-17.83\%) and linoleic acid content $(0.10-4.72 \%)$ were acceptable. Their differences between the predicted value and the measured value were in accordance with the standard errors of estimation. The FTIRbased MLR models might provide a feasible solution for the FA analysis of SSO. 
Table 4 The FTIR common bands of sunflower seed oils

Intensity of common FTIR band [code/wavenumber $\left(\mathrm{cm}^{-1}\right)$ ]

\begin{tabular}{|c|c|c|c|c|c|c|c|c|c|c|c|}
\hline Sample & $1 / 2924$ & $2 / 2854$ & $3 / 1745$ & $4 / 1464$ & $5 / 1400$ & $6 / 1379$ & $7 / 1240$ & $8 / 1161$ & 9/1099 & $10 / 966$ & $11 / 724$ \\
\hline \multicolumn{12}{|c|}{ Uncooked sunflower seed oils } \\
\hline A1 & 10.66 & 6.86 & 10.07 & 3.68 & 1.23 & 2.27 & 3.87 & 8.73 & 4.61 & - & 5.33 \\
\hline B1 & 10.70 & 7.00 & 10.38 & 3.87 & 1.32 & 2.35 & 3.99 & 8.96 & 4.74 & 1.80 & 6.36 \\
\hline B2 & 10.40 & 6.92 & 10.56 & 4.01 & - & 2.49 & 4.17 & 9.18 & 4.92 & 2.09 & 6.99 \\
\hline B3 & 10.55 & 6.72 & 9.70 & 3.37 & 1.04 & 2.11 & 3.79 & 8.67 & 4.53 & 1.56 & 5.40 \\
\hline C1 & 13.38 & 9.59 & 12.19 & 5.84 & 3.80 & 4.80 & 6.37 & 10.94 & 7.04 & 3.87 & 8.58 \\
\hline $\mathrm{C} 2$ & 11.49 & 7.33 & 10.10 & 3.79 & 1.94 & 2.99 & 4.58 & 9.14 & 5.52 & 1.99 & 7.25 \\
\hline C3 & 11.50 & 7.30 & 10.08 & 3.85 & 2.06 & 3.10 & 4.66 & 9.11 & 5.64 & 1.99 & 6.99 \\
\hline $\mathrm{C} 4$ & 11.43 & 7.32 & 10.30 & 4.04 & 2.18 & 3.20 & 4.79 & 9.29 & 5.72 & 2.20 & 7.39 \\
\hline C5 & 11.50 & 7.49 & 10.44 & 4.10 & - & 3.16 & 4.75 & 9.34 & 5.64 & 2.24 & 7.46 \\
\hline C6 & 10.26 & 6.20 & 9.18 & 3.08 & 1.11 & 2.12 & 3.67 & 8.21 & 4.57 & 1.11 & 4.98 \\
\hline C7 & 10.93 & 6.06 & 8.21 & 2.31 & 1.10 & 2.11 & 3.58 & 7.47 & - & - & 4.22 \\
\hline C8 & 11.03 & 6.19 & 8.31 & 2.44 & 1.14 & 2.19 & 3.61 & 7.53 & - & - & 4.23 \\
\hline C9 & 11.54 & 7.62 & 9.71 & 3.83 & 1.98 & 2.91 & 4.62 & 9.13 & 5.38 & 2.08 & 5.77 \\
\hline C10 & 10.23 & 6.25 & 8.48 & 2.68 & 0.79 & 1.74 & 3.54 & 8.13 & 4.37 & - & 4.77 \\
\hline C11 & 11.96 & 6.87 & 8.81 & 2.57 & 1.49 & 2.47 & 3.89 & 7.73 & - & - & 5.31 \\
\hline D1 & 10.79 & 6.75 & 9.23 & 3.33 & 1.42 & 2.42 & 4.15 & 8.80 & 5.08 & 1.65 & 5.80 \\
\hline E1 & 10.05 & 6.22 & 8.69 & 2.84 & 0.91 & 1.85 & 3.62 & 8.24 & 4.46 & - & 4.54 \\
\hline E2 & 11.50 & 6.79 & 9.13 & 3.39 & 1.96 & 2.96 & 4.45 & 8.44 & - & 1.35 & 4.67 \\
\hline E3 & 11.42 & 6.65 & 9.17 & 3.48 & 2.12 & 3.11 & 4.59 & 8.53 & - & 1.42 & 5.06 \\
\hline E4 & 10.83 & 6.75 & 9.01 & 3.30 & 1.41 & 2.31 & 3.96 & 8.42 & 4.83 & 1.34 & 4.52 \\
\hline E5 & 11.62 & 6.83 & 8.46 & 2.83 & 1.59 & 2.56 & 4.19 & 8.12 & - & 0.93 & 4.22 \\
\hline E6 & 10.31 & 6.71 & 9.79 & 3.62 & 1.49 & 2.43 & 3.90 & 8.52 & 4.76 & 1.54 & 5.06 \\
\hline E7 & 11.86 & 7.62 & 9.82 & 3.99 & 2.44 & 3.34 & 4.73 & 8.74 & 5.78 & 1.83 & 5.77 \\
\hline E8 & 9.80 & 6.17 & 9.63 & 3.16 & 1.00 & 2.00 & 3.57 & 8.44 & 4.48 & 1.22 & 4.88 \\
\hline E9 & 10.99 & 6.67 & 8.90 & 3.03 & 1.52 & 2.56 & 4.05 & 8.39 & 5.10 & 1.28 & 5.03 \\
\hline E10 & 12.04 & 6.97 & 8.56 & 2.85 & 2.11 & 3.10 & 4.58 & 8.27 & - & 1.09 & 5.37 \\
\hline E11 & 9.32 & 5.69 & 10.40 & 3.29 & 0.88 & 1.94 & 3.59 & 8.65 & 4.49 & 1.42 & 6.69 \\
\hline F1 & 12.01 & 6.98 & 9.43 & 3.99 & 2.95 & 3.87 & 5.27 & 8.91 & - & - & 5.81 \\
\hline $\mathrm{F} 2$ & 9.75 & 6.14 & 10.65 & 3.42 & 0.99 & 2.03 & 3.64 & 8.72 & 4.52 & 1.44 & 5.52 \\
\hline G1 & 10.21 & 6.48 & 9.03 & 3.30 & 1.07 & 2.02 & 3.71 & 8.43 & 4.42 & 1.40 & 4.67 \\
\hline $\mathrm{H} 1$ & 11.90 & 7.20 & 8.93 & 3.36 & 1.92 & 2.86 & 4.43 & 8.45 & - & - & 4.69 \\
\hline $\mathrm{H} 2$ & 10.88 & 6.97 & 9.83 & 3.73 & 1.96 & 2.85 & 4.31 & 8.64 & 5.35 & 1.72 & 5.43 \\
\hline H3 & 9.98 & 6.10 & 10.56 & 3.53 & 1.23 & 2.33 & 3.97 & 8.84 & 4.89 & 1.74 & 7.56 \\
\hline H4 & 10.89 & 6.25 & 8.74 & 2.38 & 0.67 & 1.76 & 3.28 & 7.60 & 4.26 & - & 4.41 \\
\hline I1 & 10.25 & 6.52 & 9.33 & 3.35 & 1.14 & 2.13 & 3.80 & 8.69 & 4.60 & 1.55 & 5.49 \\
\hline $\mathrm{I} 2$ & 12.70 & 7.21 & 8.84 & 2.59 & 1.86 & 2.79 & 4.21 & 7.74 & - & 0.38 & 5.35 \\
\hline $\mathrm{J} 1$ & 10.87 & 6.38 & 10.04 & 3.69 & 2.03 & 3.09 & 4.66 & 9.00 & 5.84 & 1.93 & 8.26 \\
\hline $\mathrm{J} 2$ & 11.15 & 7.19 & 10.41 & 3.87 & 1.50 & 2.51 & 4.09 & 8.93 & 4.91 & - & 5.22 \\
\hline J3 & 14.39 & 8.87 & 10.71 & 4.44 & 3.62 & 4.43 & 5.86 & 9.33 & - & 1.84 & 5.68 \\
\hline $\mathrm{J} 4$ & 16.47 & 9.95 & 10.80 & 4.76 & 5.98 & - & 7.01 & 9.51 & - & 2.02 & 6.04 \\
\hline J5 & 9.65 & 5.89 & 9.53 & 3.02 & 0.74 & 1.78 & 3.32 & 8.32 & 4.25 & 0.97 & 5.00 \\
\hline
\end{tabular}

Uncooked sunflower seed oils

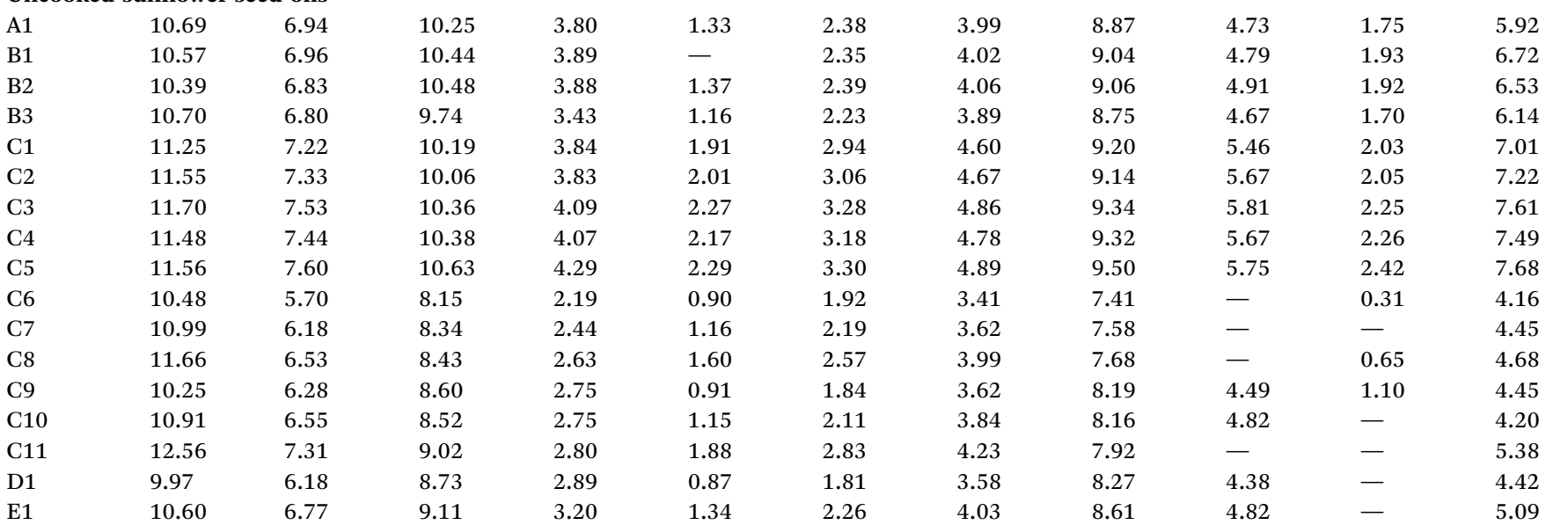


Table 4 (Contd.)

\begin{tabular}{|c|c|c|c|c|c|c|c|c|c|c|c|}
\hline \multirow[b]{2}{*}{ Sample } & \multicolumn{11}{|c|}{ Intensity of common FTIR band [code/wavenumber $\left.\left(\mathrm{cm}^{-1}\right)\right]$} \\
\hline & $1 / 2924$ & $2 / 2854$ & $3 / 1745$ & $4 / 1464$ & $5 / 1400$ & $6 / 1379$ & $7 / 1240$ & $8 / 1161$ & 9/1099 & $10 / 966$ & $11 / 724$ \\
\hline E2 & 13.05 & 8.32 & 10.70 & 5.03 & 3.63 & 4.62 & 6.03 & 9.90 & - & 2.90 & 6.38 \\
\hline E3 & 11.55 & 6.75 & 9.15 & 3.46 & 2.11 & 3.09 & 4.59 & 8.51 & - & - & 4.61 \\
\hline $\mathrm{E} 4$ & 11.47 & 7.09 & 9.06 & 3.51 & 1.84 & 2.77 & 4.31 & 8.55 & 5.32 & 1.48 & 5.11 \\
\hline E5 & 11.96 & 6.85 & 8.31 & 2.74 & 1.76 & 2.70 & 4.31 & 8.00 & - & 0.81 & 4.24 \\
\hline E6 & 10.70 & 6.91 & 9.82 & 3.68 & 1.72 & 2.63 & 4.12 & 8.59 & 5.04 & 1.60 & 5.16 \\
\hline E7 & 12.49 & 7.93 & 9.87 & 4.09 & 2.87 & 3.75 & 5.13 & 8.82 & - & 1.93 & 5.97 \\
\hline E8 & 9.89 & 5.98 & 8.78 & 2.80 & 0.95 & 1.95 & 3.50 & 8.18 & 4.50 & 1.01 & 4.88 \\
\hline E9 & 11.35 & 6.70 & 8.63 & 2.80 & 1.62 & 2.65 & 4.14 & 8.25 & - & 1.16 & 5.14 \\
\hline E10 & 13.20 & 7.75 & 8.94 & 3.42 & - & 3.99 & 5.43 & 8.75 & - & 1.61 & 5.91 \\
\hline E11 & 9.24 & 5.54 & 10.37 & 3.23 & 0.83 & 1.92 & 3.57 & 8.62 & 4.50 & 1.42 & 6.99 \\
\hline F1 & 10.51 & 6.11 & 9.22 & 3.50 & 1.92 & 2.87 & 4.41 & 8.60 & 5.51 & 1.51 & 5.08 \\
\hline $\mathrm{F} 2$ & 9.49 & 5.87 & 10.52 & 3.26 & 0.85 & 1.92 & 3.53 & 8.59 & 4.44 & 1.35 & 5.08 \\
\hline G1 & 10.36 & 6.52 & 9.02 & 3.25 & 1.14 & 2.07 & 3.73 & 8.40 & 4.50 & 1.34 & 4.50 \\
\hline H1 & 14.25 & 8.33 & 9.06 & 3.75 & - & 4.23 & 5.69 & 8.71 & - & 1.50 & 5.19 \\
\hline $\mathrm{H} 2$ & 11.32 & 7.24 & 9.87 & 3.82 & 2.23 & 3.11 & 4.51 & 8.70 & 5.63 & 1.76 & 5.62 \\
\hline H3 & 10.46 & 6.15 & 10.36 & 3.47 & 1.53 & 2.59 & 4.19 & 8.76 & 5.27 & 1.66 & 7.83 \\
\hline $\mathrm{H} 4$ & 11.82 & 6.88 & 8.94 & 2.63 & 1.23 & 2.27 & 3.72 & 7.81 & - & - & 5.03 \\
\hline I1 & 10.55 & 6.64 & 9.26 & 3.33 & 1.32 & 2.31 & 4.03 & 8.77 & 4.86 & 1.66 & 5.78 \\
\hline $\mathrm{I} 2$ & 13.22 & 7.62 & 8.98 & 2.81 & 2.24 & 3.14 & 4.53 & 7.89 & - & 0.55 & 5.57 \\
\hline $\mathrm{J} 1$ & 10.84 & 6.24 & 9.93 & 3.64 & 2.11 & 3.18 & 4.75 & 8.98 & - & 1.86 & 8.04 \\
\hline $\mathrm{J} 2$ & 12.69 & 8.02 & 10.52 & 4.12 & 2.38 & 3.38 & 4.85 & 9.08 & 5.95 & - & 5.56 \\
\hline J3 & 15.50 & 9.42 & 10.70 & 4.55 & 5.20 & - & 6.43 & 9.36 & - & 1.86 & 5.75 \\
\hline $\mathrm{J} 4$ & 17.06 & 10.29 & 10.91 & 4.92 & 5.53 & - & 7.31 & 9.63 & - & - & 6.26 \\
\hline J5 & 10.02 & 5.88 & 9.08 & 2.60 & 0.71 & 1.72 & 3.25 & 7.93 & 4.28 & 0.62 & 5.11 \\
\hline
\end{tabular}

Table 5 The FTIR characteristic-quality relationship models of sunflower seed oils established by multiple linear regression analysis ${ }^{a}$

\begin{tabular}{|c|c|c|c|c|c|c|c|}
\hline $\begin{array}{l}\text { Wavenumber } \\
\left(\mathrm{cm}^{-1}\right)\end{array}$ & $\begin{array}{l}\text { No standardized } \\
\text { coefficient }\end{array}$ & $\begin{array}{l}\text { Peroxide } \\
\text { value }\left(Y_{1}\right)\end{array}$ & Acid value $\left(Y_{2}\right)$ & $\begin{array}{l}\text { Palmitic acid } \\
\text { content }\left(Y_{3}\right)\end{array}$ & $\begin{array}{l}\text { Stearic acid } \\
\text { content }\left(Y_{4}\right)\end{array}$ & $\begin{array}{l}\text { Oleic acid } \\
\text { content }\left(Y_{5}\right)\end{array}$ & $\begin{array}{l}\text { Linoleic acid } \\
\text { content }\left(Y_{6}\right)\end{array}$ \\
\hline- & Constant & $22.816^{* *}$ & $8.890 * * *$ & -1.041 & $3.193 *$ & $-42.842^{*}$ & $145.315^{* * *}$ \\
\hline 2924 & $X_{1}$ & -0.692 & $-0.613 * *$ & -0.054 & -0.142 & $9.608^{* * *}$ & $-10.227^{* * *}$ \\
\hline 2854 & $X_{2}$ & -0.334 & $0.686^{* *}$ & 0.113 & 0.093 & -4.094 & 4.518 \\
\hline 1400 & $X_{5}$ & 0.067 & 0.028 & 0.021 & 0.004 & 0.121 & -0.081 \\
\hline 1379 & $X_{6}$ & -0.208 & 0.026 & 0.036 & 0.011 & -0.012 & 0.008 \\
\hline 1240 & $X_{7}$ & 1.086 & 0.489 & 0.204 & 0.251 & $-18.557^{* * *}$ & $20.008 * * *$ \\
\hline 1161 & $X_{8}$ & -0.693 & $-1.276 * * *$ & 0.209 & -0.184 & $6.557^{*}$ & $-7.916 * *$ \\
\hline 1099 & $X_{9}$ & 0.115 & -0.004 & 0.006 & 0.015 & -0.160 & 0.210 \\
\hline 966 & $X_{10}$ & 0.012 & -0.062 & -0.020 & 0.040 & 0.006 & -0.183 \\
\hline \multicolumn{2}{|c|}{ Determination coefficient } & $0.636^{* * *}$ & $0.562 * *$ & $0.687 * * *$ & 0.317 & $0.788^{* * *}$ & $0.763 * * *$ \\
\hline \multicolumn{2}{|c|}{ Standard error of estimation } & 0.996 & 0.230 & 0.153 & 0.175 & 2.05 & 2.30 \\
\hline \multicolumn{2}{|c|}{ Mean value of residuals } & $8.43 \times 10^{-16}$ & $-2.45 \times 10^{-14}$ & $-1.91 \times 10^{-15}$ & $-4.52 \times 10^{-1}$ & $7.26 \times 10$ & $-2.39 \times 10^{-14}$ \\
\hline
\end{tabular}

a '*', '**' and '***'represent the significance levels of $P<0.05, P<0.01$ and $P<0.001$, respectively. 
Table 6 The application of FTIR-based regression models for predicting the quality parameters of sunflower seed oils

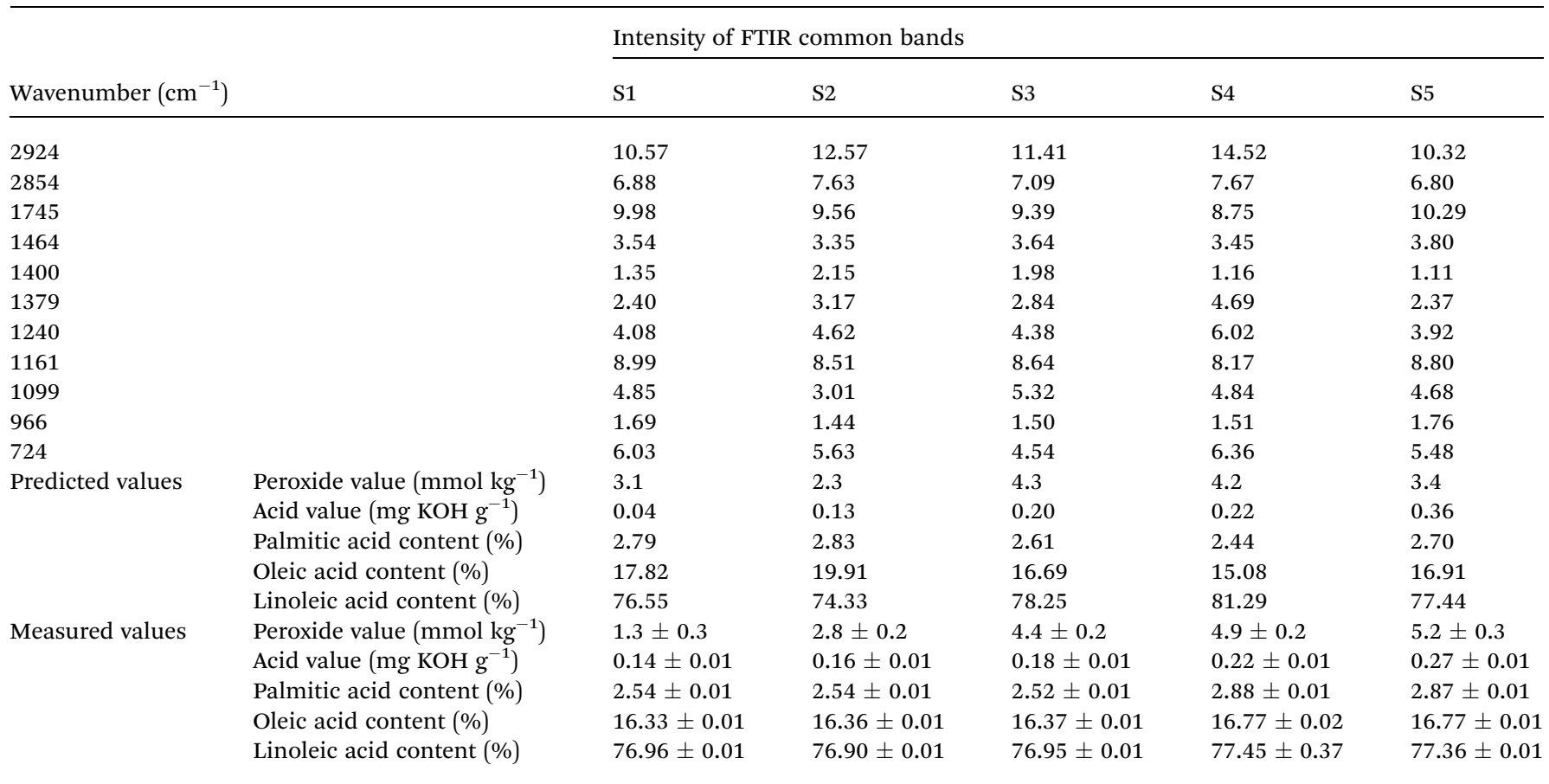

\section{Discussion}

\subsection{Factors influencing the quality of SSO}

The cooking of vegetable oil would accompany various physiochemical-reactions, such as thermal oxidation, hydrolysis, polymerization, isomerization and cyclization, due to relatively high temperatures. Those reactions lead to the formation of monomeric, polymeric, primary and secondary oxidative compounds, thereby lowering the oil quality. ${ }^{28}$ The frying-caused changes in the qualities of edible oils have attracted great attentions..$^{3,29-32}$ The related investigations mostly adopted long-time frying simulations (more than 30 min), which were hugely different from the popular Chinese cooking styles (i.e. stir-frying and pan-frying) characterized with HTST. ${ }^{9,10}$ In the present study on SSO, it was found that HTST cooking would cause a slight increase in PV, but did not obviously change AV and FA composition. According to our previous investigation on the effects of HTST conditions on the quality of SSO, its POV did not obviously change by 1-4 min-cooking in the cast iron pan at temperature lower than $150{ }^{\circ} \mathrm{C}$ possibly because the oil oxidation was nonsignificant. However, the oxidation was effectively promoted at $180{ }^{\circ} \mathrm{C}$ resulting in a significant increase of POV after 1 min of cooking. A higher cooking temperature $\left(210^{\circ} \mathrm{C}\right)$ might bring a balance between the production and decomposition of hydroperoxides with a relatively stable POV during 8 min-cooking. ${ }^{10}$ The different levels of natural and synthetic antioxidants in the SSO products might be associated with the various changes of POV responding to the HTST cooking $\left(210^{\circ} \mathrm{C}, 5 \mathrm{~min}\right) .{ }^{33}$ There might be a very small quantity of free FA produced by the hydrolysis of triacylglycerols via HTST cooking, which was consistent with the inconspicuous change of FA composition. In addition, the produced free FA could be partly volatilized during HTST cooking. ${ }^{10}$ Therefore, HTST cooking did not cause significant changes in these parameters. According the previous studies,,$^{3,7,11,13,30,32}$ it was suggested that the changes would be significantly observed after high temperature and long time cooking, such as frying $\left(150-200{ }^{\circ} \mathrm{C}\right)$ for more than $30 \mathrm{~min}$.

It has been widely recognized that the products of same vegetable oil might differ in chemical composition due to geographical, agronomic or technological differences. The seed oil of eight sunflower varieties, grown at 10 locations across Canada in 1963 and 14 locations in 1964, showed highly significant differences between varieties and between stations in the mean contents of stearic acid, oleic acid and linoleic acid, but the difference in palmitic acid content was not significant. ${ }^{34}$ Here, we make a betweengroup comparison on the quality of SSO products from different countries (Turkey, Spain, Ukraine, Russia and China) or produced by different technologies (Table 7). The products exhibited no significant difference between countries in PV, AV, stearic acid content, palmitic acid content and oleic acid content $(P>0.05)$. The linoleic acid contents of products from Ukraine and China showed no significant difference $(P>0.05)$, but were both higher than that of Turkish products $(P<0.05)$. Compared with pressing oils, extracting oils had an obviously higher mean value of AV (possibly due to the readily solubility of free FA in organic solvent) and a slightly lower mean value of PV (possibly due to the presence of larger amounts of antioxidants, such as tocopherols, phenolics and sterols).$^{35}$

A previous study indicated that the PV and AV of SSO significantly increased after long-time storage. ${ }^{8}$ The similar results were confirmed in the present work, i.e. the PV and AV increased with the prolonging of shelf time which was identified as the time span between the dates of production and test (Table 7). Especially, products shelved 19-24 months had 
Table 7 Analysis on the factors related to the quality differences of $\mathrm{SSO}^{a}$

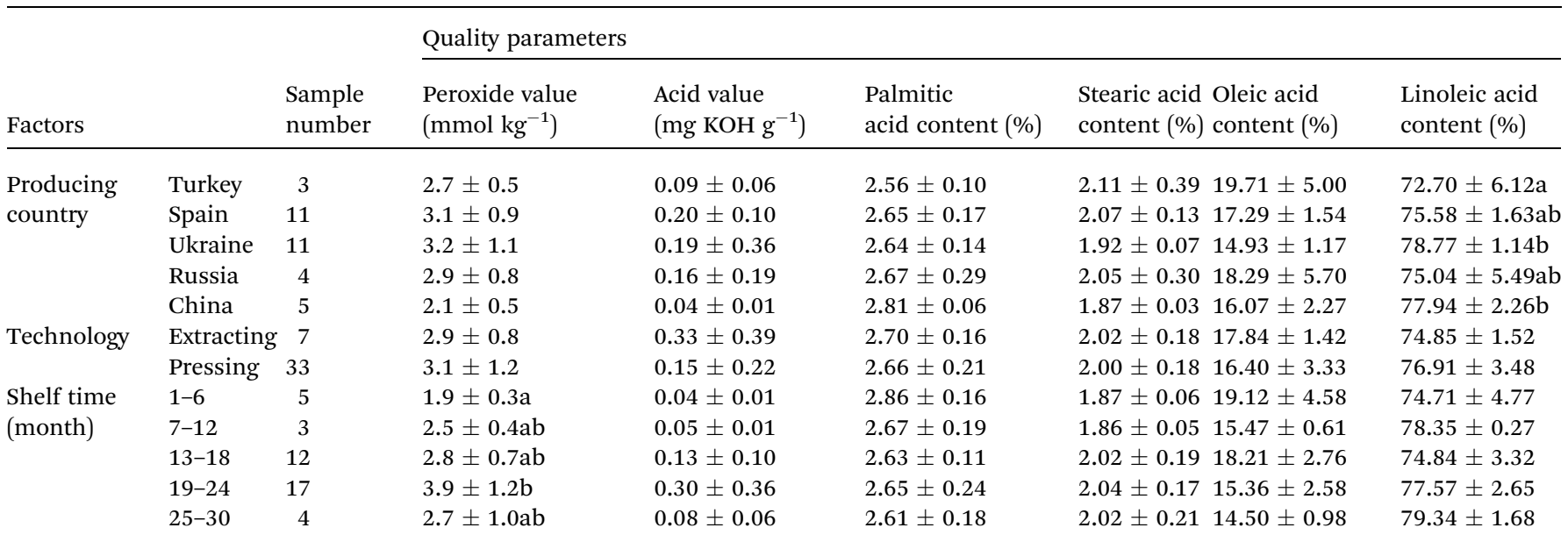

${ }^{a}$ The between-group difference $(P<0.05)$ is indicated by different lowercase-letters. 'Shelf time' means the time span between the dates of production and test of sunflower seed oil product.

a higher mean value of PV compared to those shelved 1-6 months $(P<0.05)$. The shelf time-related deterioration of SSO depended to a great extent on the temperature of storage, the exposure to light, the impermeability of container to oxygen and the level of antioxidants. ${ }^{\mathbf{8} 36}$ Products stored for longer time would suffer more negative effects by auto-oxidation and photooxidation, as well as more consumption of antioxidants. It was reported that the $\alpha$-tocopherol level fell by around $90 \%$ in olive oil after 9 month storage at $20{ }^{\circ} \mathrm{C} .{ }^{36}$ Moreover, free FA resulted from the hydrolysis of triacylglycerols could catalyze the further hydrolysis reaction, leading to the increase of susceptibility to hydrolytic rancidity. ${ }^{36}$ Generally, the FA composition of vegetable oils remained more or less constant during storage regardless of the storage conditions. ${ }^{36-38}$ This work indicated that the shelf time showed no obvious relationship with the differences in FA composition as seen in Table 7.

\subsection{Relationship between FTIR spectrum and quality}

FTIR spectroscopy allows the qualitative determination of organic compounds as the characteristic vibration mode of each molecular group produces the specific band in the spectrum and the band intensity is proportional to concentration. ${ }^{14}$ Many studies have confirmed the availabilities of FTIR-based chemometrics analysis for the determination of PV, AV and FA percentage in edible oils. ${ }^{\mathbf{1 6}, 20}$ In some of them, only a specific band or region has been taken into account for a certain parameter, such as, $724 \mathrm{~cm}^{-1}$ or $1160 \mathrm{~cm}^{-1}$ band for saturated acyl groups, $966 \mathrm{~cm}^{-1}$ band or $3700-3400 \mathrm{~cm}^{-1}$ region for $\mathrm{PV}$, $1100 \mathrm{~cm}^{-1}$ or $1395 \mathrm{~cm}^{-1}$ band for monounsaturated acyl groups, and $1711 \mathrm{~cm}^{-1}$ band for free FA. ${ }^{16-19}$ In the present work, different relationships between band and parameter were obtained by Pearson's correlation analysis (data not shown): the intensity of $1161 \mathrm{~cm}^{-1}$ band had a positive correlation with polyunsaturated fatty acid content and a negative correlation with oleic acid content $(P<0.05)$, and that of $966 \mathrm{~cm}^{-1}$ band showed a negative correlation with palmitic acid content $(P<$
0.05). The intensity of $1464 \mathrm{~cm}^{-1}$ band negatively responded to monounsaturated fatty acid content, but was positively related to polyunsaturated fatty acid content and linoleic acid content $(P<0.05)$. In addition, the negative relationship between $1379 \mathrm{~cm}^{-1}$ band intensity and palmitic acid content was confirmed $(P<0.05)$, as well as that between $1240 \mathrm{~cm}^{-1}$ band intensity and saturated fatty acid content $(P<0.05)$. It was suggested that a specific parameter would be associated with various bands, namely several FTIR bands needed to be considered in determination for a concrete parameter. Eleven selected bands variously contributed to the determination of SSO quality parameters (AV, PV, C16:0, C18:0, C18:1 and C18:2) as seen in Table 5. Specially, the number of selected variables for the simultaneous determination of several parameters (AV, PV, C16:0, C18:0, C18:1, C18:2 and C18:3) was varied between 1213 and 1302 in the $4000-550 \mathrm{~cm}^{-1}$ region. $^{20}$

HTST cooking would cause slight changes in the intensity of bands appeared at 2924, 2854, 1379, 1240 and $966 \mathrm{~cm}^{-1}$. The minor decrease of $1745 \mathrm{~cm}^{-1}$ band intensity might respond to the variation in chain length, unsaturation degree and form of the acyl groups because of the production of hydroperoxides, acids or other oxidation products during the heating process. ${ }^{20}$ The bands at 2924 and $2854 \mathrm{~cm}^{-1}$, which were known as the absorption zone of $\mathrm{C}-\mathrm{H}$ stretching vibration of methylene and terminal methyl groups of FA chains, would be changed because of the production of functional groups of saturated aldehydes or other secondary oxidation products by heating. ${ }^{18}$ The increased absorption at $966 \mathrm{~cm}^{-1}$ after cooking might be due to the $\mathrm{C}-\mathrm{H}$ out-of-plane deformation of isolated trans double bonds or some trans conjugated unsaturated fatty acids, and the decreased absorption at $1745 \mathrm{~cm}^{-1}$ might be related to the degradation of esters. ${ }^{39}$

\section{Conclusion}

SSO recognized as a healthy vegetable oil attracts great attentions in China, particularly its imports possess a larger market 
share compared to its homemade amount. By analyzing the chemical characteristics including PV, AV and FA composition, the quality diversity of SSO products was confirmed. Their major differences in quality might be related to different origins and shelf times. The product with shelf time more than 18 months would have a relatively low quality. HTST cooking did not cause significant changes in the quality parameters of SSO, suggesting that SSO is thermally stable for the typical ways of Chinese cooking. In addition, the quality diversity could be also detected by FTIR spectroscopy due to the specific relationship between FTIR characteristic and quality. Accordingly, the cooked oils could be completely distinguished from the uncooked ones by the OPLS-DA of FTIR spectra. Moreover, the MLR models of palmitic acid content, oleic acid content and linoleic acid content, established by the intensities of FTIR common bands as independent variables, were acceptable and could be preliminarily used for the determination of FA composition. This work facilitates the comprehensive understanding on the quality characteristics of SSO products. However, more characteristics directly or indirectly related to their qualities, such as volatile flavor compounds, antioxidants and oxidative products, need to be further investigated.

\section{Conflicts of interest}

There are no conflicts to declare.

\section{Acknowledgements}

This work was supported by the National Key R\&D Program of China (2016YFD0401103).

\section{References}

1 S. Şahin, E. Sayim and R. Samli, Korean J. Chem. Eng., 2017, 34, 2284-2292.

2 A. Bendini, S. Barbieri, E. Valli, K. Buchecker, M. Canavari and T. G. Toschi, Eur. J. Lipid Sci. Technol., 2011, 113, 1375-1384.

3 R. Upadhyay, S. Sehwag and H. Niwas Mishra, Food Chem., 2017, 218, 496-504.

4 W. Zhang, Agricultural Outlook, 2018, vol. 11, pp. 4-8.

5 R. Wang, China Oils Fats, 2016, 41, 1-3.

6 E. E. Perez, A. A. Carelli and G. H. Crapiste, J. Am. Oil Chem. Soc., 2004, 81, 245-249.

7 G. Budryn, E. Nebesny, D. Żyżelewicz and J. Oracz, LWT-Food Sci. Technol., 2014, 59, 467-478.

8 R. Romanić, E. Dimić, V. Lazić and V. Vujasinović, Acta Aliment., 2009, 38, 319-327.

9 Y. Cui, P. Hao, B. Liu and X. Meng, Food Chem., 2017, 233, 77-84.

10 J. Yao, C.-X. Zhang, Y.-R. Cai, H.-F. Wang, Y. Yi and L.-M. Wang, J. Food Saf. Qual., 2018, 9, 1072-1078.

11 F. M. A. Rehab and A. M. El-Anany, J. Food Process. Technol., 2012, 3, 176.

12 L. Silva, J. Pinto, J. Carrola and F. Paiva-Martins, Food Chem., 2010, 121, 1177-1187.
13 M. Bensmira, B. Jiang, C. Nsabimana and T. Jian, Food Res. Int., 2007, 40, 341-346.

14 N. Vlachos, Y. Skopelitis, M. Psaroudaki, V. Konstantinidou, A. Chatzilazarou and E. Tegou, Anal. Chim. Acta, 2006, 573574, 459-465.

15 J. Vilela, L. Coelho and J. M. M. M. de Almeida, Cogent Food Agric., 2015, 1, 1020254.

16 N. Cebi, M. T. Yilmaz, O. Sagdic, H. Yuce and E. Yelboga, Food Chem., 2017, 225, 188-196.

17 M. D. Guillén and N. Cabo, J. Am. Oil Chem. Soc., 1997, 74, 1281-1286.

18 A. Bendini, L. Cerretani, F. Di Virgilio, P. Belloni, M. BonoliCarbognin and G. Lercker, J. Food Qual., 2007, 30, 424-437.

19 J. Shang, X. Wu, K. Hu, Z. Huyan, Q. Li and X. Yu, Anal. Methods, 2018, 10, 3675-3679.

20 M. Mahboubifar, S. Yousefinejad, M. Alizadeh and B. Hemmateenejad, J. Iran. Chem. Soc., 2016, 13, 2291-2299.

21 Q. Zhang, C. Liu, Z. Sun, X. Hu, Q. Shen and J. Wu, Food Chem., 2012, 132, 1607-1613.

22 B. Innawong, P. Mallikarjunan, J. Irudayaraj and J. E. Marcy, LWT-Food Sci. Technol., 2004, 37, 23-28.

23 M. J. Lerma-García, G. Ramis-Ramos, J. M. Herrero-Martínez and E. F. Simó-Alfonso, Food Chem., 2010, 118, 78-83.

24 National Health and Family Planning Commission of China, Standard, 2016, GB5009.227.

25 National Health and Family Planning Commission of China, Standard, 2016, GB5009.229.

26 National Health and Family Planning Commission of China and China Food and Drug Administration, Standard, 2016, GB5009.168.

27 General Administration of Quality Supervision, Inspection and Quarantine of China and Standardization Administration of China, Standard, 2017, GB/T 10464.

28 N. K. Andrikopoulos, N. Kalogeropoulos, A. Falirea and M. N. Barbagianni, Int. J. Food Sci. Technol., 2002, 37, 177-190.

29 S. F. Hamed, G. A. abo El-Wafa, A. El-Ghorab and T. Shibamoto, J. Am. Oil Chem. Soc., 2011, 88, 1851-1855.

30 R. Farhoosh and M. H. Tavassoli-Kafrani, Food Chem., 2011, 125, 209-213.

31 M. D. Juárez, C. C. Osawa, M. E. Acuña, N. Sammán and L. A. G. Gonçalves, Food Control, 2011, 22, 1920-1927.

32 Y. Liu, J. Li, Y. Cheng and Y. Liu, LWT-Food Sci. Technol., 2019, 101, 331-341.

33 R. Kowalski, Food Chem., 2009, 112, 820-830.

34 E. D. Putt and R. B. Carson, J. Am. Oil Chem. Soc., 1969, 46, 126129.

35 A. S. Bhatnagar and A. G. Gopala Krishna, J. Am. Oil Chem. Soc., 2014, 91, 1205-1216.

36 X. Li, H. Zhu, C. F. Shoemaker and S. C. Wang, J. Am. Oil Chem. Soc., 2014, 91, 1559-1570.

37 E. N. Guiotto, V. Y. Ixtaina, S. M. Nolasco and M. C. Tomás, J. Am. Oil Chem. Soc., 2014, 91, 767-776.

38 A. I. Méndez and E. Falqué, Food Control, 2007, 18, 521-529. 39 J. Y. Chen, H. Zhang, J. Ma, T. Tuchiya and Y. Miao, Int. J. Anal. Chem., 2015, 2015, 185367. 